\title{
Symposium review: The most important factors affecting adoption of precision dairy monitoring technologies*
}

\author{
A. E. Stone† ${ }^{\circ}$ \\ Department of Animal and Dairy Sciences, Mississippi State University, Mississippi State 39762
}

\section{ABSTRACT}

Precision dairy monitoring involves the use of technologies to measure physiological, behavioral, and production indicators on individual animals to detect events of interest. Estrus, disease, and calving detection are common applications, although estrus detection is the most tested and used. Many precision dairy monitoring technologies (PDMT) are commercially available and are being used in research and on farms. As a result, a common question from researchers and producers alike is, "what PDMT should I buy?" The answer to this question is inherently complicated because it depends on many factors, some of which researchers have yet to explore. The objective of this paper is to examine the less quantitively researchable aspects of PDMT adoption and use on-farm. This will be done through 3 lists of 5 , determined from published theory and my own experience. First, the 5 main factors that influence adoption of an innovation: (1) relative advantage, (2) compatibility, (3) complexity, (4) trialability, and (5) observability. Each of these factors is at play to a different extent in the 5 adopter categories: (1) innovators, (2) early adopters, (3) early majority, (4) late majority, and (5) laggards. From my experience and research, the top PDMT are those that improve (1) farm efficiency; (2) farm economics; (3) decisionmaking; (4) animal welfare; and (5) producer happiness. Implementing PDMT on a farm is an enormous and potentially expensive decision. As this part of the industry continues to progress, the potential for different PDMT is endless. Sound research and producer feedback are imperative to ensuring that PDMT continue to improve and become more widely adopted. Key words: precision, monitoring, dairy

Received June 23, 2019.

Accepted March 24, 2020.

*Presented as part of the Production, Management, and the Environment: Profitability and Sustainability Symposium at the ADSA Annual Meeting, Cincinnati, Ohio, June 2019.

†Corresponding author: amanda.stone@msstate.edu

\section{INTRODUCTION}

Precision dairy monitoring technologies (PDMT) monitor behavioral, physiological, or production indicators to detect individual animal disease, estrus, welfare (Stone et al., 2017), or impending calving (Borchers et al., 2017). Many PDMT are commercially available and are being used in research and on farms, several of which were validated in Borchers et al. (2017). Precision dairy monitoring technologies can be placed on or in the cow, but many technologies are now available in the parlor, in robots, and in an exit or feed alley. Until recently, most PDMT worked with 3-axis accelerometers with different algorithms applied, but advanced imaging is now becoming more commonly used.

To date, PDMT evaluations have focused mainly on automated estrus detection, aimed to supplement or replace visual estrus detection (Dolecheck et al., 2015). However, PDMT also have the potential to detect disease early and maximize individual animal potential. In other words, PDMT may alert producers to cows at risk for a disease instead of the current method of identifying cows that are already sick (Itle et al., 2015). For example, decreased activity could be a sign of illness (Stone, 2017) and decreased lying time could be a sign of pain (Cook et al., 2007).

Researchers are actively pursuing validation of and research on commercially available PDMT. Numerous publications evaluating PDMT are available (Dolecheck et al., 2015; Pereira et al., 2018; Mayo et al., 2019, among others). Many validation studies report traditional statistical performance indicators such as sensitivity (the proportion of gold standard-positive cases that are correctly detected as being positive for the event of interest) and specificity (the proportion of gold standard-negative cases that are correctly detected as negative for the event of interest; Kamphuis et al., 2016). Data cleaning, statistical analysis, and interpretation of results are often difficult.

Comparing performance indicators between studies, and thus between technologies and algorithms, is also extremely difficult because studies have used a variety of gold standards to define events of interest (Hogeveen 
et al., 2010). Claycomb et al. (2009) demonstrated that even small differences in gold standard definitions had a large effect on the number of true cases used for evaluation purposes. Additionally, even when gold standards between studies are similar, comparison of results remains difficult due to differences in the inclusion or exclusion criteria used to create data sets to develop and validate detection models.

Producers interested in adopting a PDMT are tasked with choosing one that will serve their needs well, and for as long as possible, to justify their investment. When producers are deciding on purchasing a PDMT, decisions involve more than research data and are heavily based on qualitative information. A producer's perception of the qualities of a PDMT - not those determined by experts - affects adoption rates (Rogers, 1995).

The 5 main factors that influence adoption of an innovation are (1) relative advantage, (2) compatibility, (3) complexity, (4) trialability, and (5) observability. Each of these factors is at play to a different extent in the 5 adopter categories: (1) innovators, (2) early adopters, (3) early majority, (4) late majority, and (5) laggards (Rogers, 1962).

\section{ADOPTION INFLUENCES AND OPPORTUNITIES}

\section{Adoption of Innovation Influences}

Rogers (1962) explained the theory of innovation diffusion, which has been applied to many fields from public health to dairy science. Many factors account for how and when people decide to adopt an innovation, in this case PDMT, and the potential adopter's perceived characteristics of the innovation help explain their different rates of adoption. The 5 perceived characteristics are (1) relative advantage, (2) compatibility, (3) complexity, (4) trialability, and (5) observability. These 5 characteristics account for 49 to $87 \%$ of the variance in innovation adoption rates (Rogers, 1995).

\section{Relative Advantage}

Relative advantage is the degree to which an innovation is perceived as better than the already implemented option it displaces. This is often equated with economics of the innovation, which holds great importance related to PDMT and will be discussed later in this paper. However, economics may actually matter less to the potential adopter than less-objective measures because the relative advantage is in the eyes of the potential adopter. What matters is that the potential adopter sees the PDMT as advantageous enough for them, and if they do, they will adopt (Rogers, 1962). A simple example of relative advantage is the milk- ing machine. It, too, was a technology that had to go through the technology adoption process in the same way that PDMT now are. However, the relative advantage of using a machine to milk versus hand-milking is quite obvious and universally understood, facilitating adoption.

Other relative advantage factors besides economics include convenience, social factors (like whether or not the producers' friends or competitors have already adopted a PDMT), insight from trusted individuals and advisors, having more managerial tasks versus checking cows more often, having more time away from the farm to spend with family, lessening the need for hired labor, and producer happiness. Producer perception of PDMT remains relatively unknown to manufacturers (Borchers and Bewley, 2015). Manufacturers of PDMT should seek out producer feedback and insights to improve their usefulness and adoption.

\section{Compatibility}

Compatibility is the degree to which an innovation is perceived as being consistent with existing values, past experiences, and needs of potential adopters. Something that goes against the prevalent values and norms of a society, large (national industry) or small (regional or even neighborhood farms), will not be adopted as rapidly as something that follows those norms. To adopt incompatible innovations, the value systems have to change (Rogers, 1962). The values and norms of the dairy industry have certainly evolved over the years, but still much of what exists was created generations ago and passed down to the current producers.

Many technologies have not been compatible with the Amish society historically, but the needs of potential adopters may be changing and building compatibility. Cross (2014) explored changes in Amish dairy farming in Wisconsin and found that some producers have started adopting technologies, such as bulk tanks and milking machines, that were previously denied for religious and lifestyle reasons. The author found that changes in use of technology were carefully contained within certain Amish settlements, mostly new settlements, instead of changing the existing values and norms of the already settled groups. Additionally, the decision to use a bulk tank to store milk was necessitated by the absence of a local buyer for their can milk.

\section{Complexity}

Complexity is the degree to which an innovation is perceived as difficult to implement and understand. Innovations that are simpler to understand will be adopted more quickly than innovations that require new 
skills or understanding (Rogers, 1962). For example, bovine recombinant somatotropin (rbST) has a low complexity. Producers could implement the shot into an existing routine and they understood that milk yield would increase. Research confirmed this (VanBaale et al., 2005 and others) and rbST was positively received because of the increased yield.

With PDMT, the complexity is greater. The technologies themselves and the accompanying software are somewhat complicated, particularly for producers who may have only started using computers in the last decade. The outputs are also often complex, partly because they could be measuring variables that humans simply cannot measure (e.g., core body temperature, rumination time, eating time) so knowing what they mean is not as simple as understanding something like milk yield, which the industry has been able to measure and observe for many years.

Additionally, because these data have not been readily available until recently, researchers are working to test different statistical methods and models that accurately assess PDMT data while understanding that all cows are not the same. In other words, even researchers have never had access to this much biological, physiological, and behavioral data before and thus interpretation and understanding are sometimes slow. For example, producers can obtain individual cow SCC information at each milking each day with in-line SCC machines (Kamphuis et al., 2008). However, equating mastitis with a specific SCC over a specified time period has yet to be established.

When using PDMT to predict estrus, the choices are simple: breed or not breed and when. If a cow is bred when she was not ready, she simply won't become pregnant and another opportunity will be presented when she is ready. However, when we start to apply PDMT to animal disease and welfare aspects, responses and options are not so clear cut. If a PDMT implies an animal is sick, the decisions that lie ahead are complicated and require expertise as well as experience. Marra et al. (2003) hypothesized that some crop precision technologies are over-adopted relative to their true value. Correctly evaluating precision technologies is difficult and complex but their apparent attractiveness when considered from a simple perspective sometimes overrides the logical component. The fixed costs of some technologies may result in investment delays.

\section{Trialability}

Trialability is the degree to which an innovation may be experimented with on a limited basis. New ideas that can be tried before buying will generally be adopted more quickly than innovations that cannot. An innovation that is "trialable" presents less uncertainty to the individual who is considering it for adoption, because it is possible to learn by doing (Rogers, 1962). Although it would not be without complications, PDMT companies allowing a trial period may facilitate more adoptions, similar to how car dealerships allow potential buyers to take a car home for the night before purchasing. This practice lets people evaluate the things that are important to them while seeing if the relative advantage, compatibility, and complexity fit their needs. This takes away some of the uncertainty and removes some risk because no money has yet been invested. Producers are sometimes able to visit other farms that have PDMT to see it in action, but differences exist on every farm from management style, facilities, and importance of different factors that would affect PDMT adoption.

\section{Observability}

Observability is the degree to which the results of an innovation are visible to others. The easier it is for individuals to see the results of an innovation, the more likely they are to adopt (Rogers, 1962). Producers tend to trust the opinions and experiences of other producers more than they trust the opinions of others (non-producers). For example, DeLong et al. (2017) explained that the percent of producers using other producers as information sources related to mastitis was $77 \%$, second only to veterinarians (90\%). Veterinarians, in this case, may actually be an indirect source of information from producer peers because veterinarians visit many farms daily. Comparatively, only $49 \%$ of producers relied on information about mastitis from co-op representatives and 32\% from extension specialists (DeLong et al., 2017).

Producers listening to other producers is positive in many aspects, but it also can create a negative perception in others' minds if the experience being shared is a negative one. If a producer says that a PDMT is perfect (or, conversely, horrible) for their farm and suggests that everyone else should also adopt it (or not adopt it), others may listen, even though the right choice of PDMT may differ among individual farms and producers.

\section{Adopter Categories}

Each of the above factors is at play to a different extent in the 5 adopter categories: (1) innovators, (2) early adopters, (3) early majority, (4) late majority, and (5) laggards (Rogers, 1962). We can think of this as how risk-averse a person is: at the two extremes innova- 
tors are risk-takers and laggards are extremely riskaverse. Rogers explains that innovators adopt a new technology simply because it is new. Early adopters create and express their opinions, which propel trends. They tend to be concerned with maintaining a reputation of being ahead of the curve. The early majority make adoption decisions based on utility and practical benefit as opposed to reputation or the newness factor that the previous 2 groups are concerned with. The late majority is more cautious than the early majority and need more information and thought before adopting. Last, the laggards are slow to adopt new technology and only do so when they are forced to, either by some external force (e.g., their milk cooperative ending their contract if they do not comply) or because everyone else already has already adopted the technology.

\section{Technology Aspects}

Researchers and producers alike are interested in finding the best PDMT available. In general, the top technologies are those that improve, in no specific order, (1) farm efficiency, (2) farm economics, (3) decision-making, (4) animal welfare, and (5) producer happiness.

Some things simply are not efficient and could be improved by implementing PDMT. For example, visually observing cows for signs of estrus for a few hours each day is a task that could be relied upon with PDMT so that producers could use that time for high-level jobs such as evaluating test results (e.g., pregnancy or milk cultures) and implementing management changes to improve the herd. Mayo et al. (2019) tested 6 PDMT, all of which were capable of detecting estrus at least as effectively as visual observation. Additionally, 4 of the 6 PDMT that reported estrus alerts correctly detected 15 to $35 \%$ more cows than visual observation 4 times per day.

Not all tasks on the farm are so easily designated, though. If a PDMT existed that could detect mastitis early and accurately, producers may no longer see the need to be in the parlor to look for clinical signs of mastitis. However, producers accomplish other important tasks in the parlor such as using mastitis prevention methods, evaluating cows for other diseases, giving medicine as needed, and more. Hired labor could handle some of these tasks, but arguably no one cares as much about what goes on in the parlor as the producer, so things may be missed, which may then require more work on the producer's end to fix the problem later on. An automated milking system could handle some of these other tasks just as well as the producer or hired labor, but milking systems are currently unable to ac- curately evaluate cows for diseases other than mastitis and, in some systems, ketosis. Implementing PDMT in the parlor and allowing the producer to check cows in other ways or at other times is likely more efficient. The level of efficiency of getting a producer out of the parlor would depend heavily on what they decide to use that time for instead, which would likely vary greatly between farms.

Precision dairy monitoring technologies need to be a solution to a problem, not a solution searching for an application, which sometimes occurs, particularly when non-agricultural companies join the market. They also cannot be another problem for a producer to add to their already full plate. These technologies provide copious amounts of information, which can sometimes be overwhelming. The ability to process data and present information in an accurate and easy-to-understand manner is important so that producers can utilize the information as intended. The producers gaining the most benefit from PDMTs are the ones implementing them as part of their everyday standard operating practices and using 3 of their most important senses to understand the data: common sense, cow sense, and business sense.

Farm economics is arguably the most concrete but least important aspect of PDMT adoption. As explained earlier, economics may not be as important to producers as industry representatives believe it should be because many other personal and professional factors play a large role in the decision to implement PDMT. Producers sometimes express that PDMT are more for large farms than for small farms, which likely plays a subconscious role in the adoption decision. Fixed adoption costs can be spread across a greater number of cows in large herds, but variable costs such as the price per leg tag may be the same per cow. Smaller farms logically also have a smaller labor force, spreading each person over more tasks and potentially decreasing the value or success of at least some of those tasks. Large farms may have personnel who are tasked with watching for estrus multiple times per day without having to focus on other tasks simultaneously.

Gargiulo et al. (2018) explained that Australian producers with more than 500 cows adopted between 2 and 5 times more PDMT (e.g., automatic cup removers, automatic milking parlor wash systems, electronic cow identification systems, and herd management software) than producers with smaller herds. Although the currently adopted PDMT were mostly ones that reduce labor, respondents indicated that by 2025 adoption of PDMT would increase.

Implementing PDMT on a farm is an enormous and potentially expensive decision that should not be taken 
lightly. If a producer is struggling to make financial ends meet, investing in a PDMT is likely not the best decision when money would probably be better served into increasing milk production through nutrition, genetics, mastitis prevention, or facilities. If a producer has the financial means to make improvements beyond simple and inexpensive fixes, then PDMT may be a sound investment if it also provides other benefits that are important to them.

Simply putting PDMT on cows will not improve farm economics - or anything else. Collecting information to make better decisions is important. But doing something with that information is even more important. For example, if a producer invests in a leg-based estrus detection PDMT but ignores most of the estrus alerts, it is not improving the farm. If a producer invests in the same technology and can breed based on the information but also uses the information to better understand underlying reproductive issues within the farm, management decisions can be made to improve the herd as a whole.

Animal welfare has always been important to producers but has become increasingly concerning in recent years as animal rights groups have targeted aspects of dairy farming and created values among consumers. Implementing PDMT has the potential to improve animal welfare in several facets. Fraser et al. (1997) cited 3 overlapping animal welfare concerns: biological functioning, affective state, and natural living. For example, a cow with clinical mastitis may be unable to comfortably lie down or eat well (natural living), will experience pain (affective state), and will have reduced milk production (biological functioning). von Keyserlingk et al. (2009) explained that much of the concern about disease arises from the suffering the animal undergoes but improvements in one welfare aspect can improve the other aspects. Therefore, a PDMT that is able to detect mastitis at the start of or before clinical signs would enable a producer to treat the cow more rapidly, decreasing the amount and duration of pain experienced (affective state). This reduction in pain may allow the cow to lie down and eat well again (natural living) and decrease the amount of milk yield lost (biological functioning).

Producer happiness is the last aspect. Happiness is not easily or objectively measured and thus is difficult to research, but it is indirectly included with opportunity cost (e.g., an automated milking system can milk cows while the producer attends their child's baseball game, which would likely create happiness). In the simplest terms, a producer who hates change and is afraid of technology may not be happier by using PDMT, even if it means he or she gains something else in life that would make them happy.
According to Veenhoven (1991), the idea that happiness is relative was advanced by early Greek philosophers. Happiness is a complicated issue influenced by human affective state and many other variables, as explained in Veenhoven (1991). However, producer happiness in this sense is meant to be interpreted literally. Does implementing a PDMT on a producer's farm make them happy? Happiness means different things to different people based on their current circumstances and values, so, although not a concrete measure, it is still a very important one that should not be disregarded.

Some producers thrive on change and enjoy the thrill of implementing a new technology on their farms. Even though it may not make economic sense and thus may be a bad business decision, it may be a good personal decision. The difference in whether it is a good overall decision lies in whether or not they could afford to spend money on something that may only be implemented as a toy rather than a decision-making tool to improve the herd. In contrast, someone who implements a useful and economically sound PDMT on their farm may still not be happy with the results because they hear that another producer is getting better results when using it. Last, a producer who is getting a small amount of benefit out of a PDMT may be completely happy with their decision to invest because they value it on a relative scale of where things were in the past to where they currently are and may see enough change in whatever values are important to them. Therefore, happiness is important but not predictable or consistent.

\section{CONCLUSIONS}

More information than ever is available to dairy producers through PDMT. The dairy industry as a whole is experiencing substantial changes in how information is collected and utilized. Although there are many research-validated and well-implemented PDMT on the market currently, more enter the market all the time and producers are left with difficult decisions on whether to invest, when to invest, and what to invest in. Researchers often focus on the economics and usefulness of information of these PDMT, but often the intangibles are what matter to producers and should be considered when making and receiving recommendations. What one producer perceives as important may not be the same as another. From my own experience and research, the top PDMT are those that improve (1) farm efficiency, (2) farm economics, (3) decisionmaking, (4) animal welfare, and (5) producer happiness. The 3 lists of 5 in this review may help the reader better understand why the choice of PDMT investment is not as simple as might be perceived by researchers. 


\section{ACKNOWLEDGMENTS}

The author acknowledges the important support of the journal and the American Dairy Science Association for inviting this review paper and to the regional project group NC2042 (Management Systems to Improve the Economic and Environmental Sustainability of Dairy Enterprises; USDA, Washington, DC) for choosing me to present this symposium paper at the 2019 ADSA meeting. The author has not stated any conflicts of interest.

\section{REFERENCES}

Borchers, M. R., and J. M. Bewley. 2015. An assessment of producer precision dairy farming technology use, prepurchase considerations, and usefulness. J. Dairy Sci. 98:4198-4205. https://doi .org/10.3168/jds.2014-8963.

Borchers, M. R., Y. M. Chang, K. L. Proudfoot, B. A. Wadsworth, A. E. Stone, and J. M. Bewley. 2017. Machine-learning-based calving prediction from activity, lying, and ruminating behaviors in dairy cattle. J. Dairy Sci. 100:5664-5674. https://doi.org/10.3168/jds 2016-11526.

Claycomb, R. W., P. T. Johnstone, G. A. Mein, and R. A. Sherlock. 2009. An automated in-line clinical mastitis detection system using measurement of conductivity from foremilk of individual udder quarters. N. Z. Vet. J. 57:208-214. https://doi.org/10.1080/ 00480169.2009.36903.

Cook, N. B., R. L. Mentink, T. B. Bennett, and K. Burgi. 2007. The effect of heat stress and lameness on time budgets of lactating dairy cows. J. Dairy Sci. 90:1674-1682. https://doi.org/10.3168/ jds.2006-634.

Cross, J. A. 2014. Continuity and change: Amish dairy farming in Wisconsin over the past decade. Geogr. Rev. 104:52-70. https:// doi.org/10.1111/j.1931-0846.2014.12004.x.

DeLong, K. L., D. M. Lambert, S. Schexnayder, P. Krawczel, M. Fly, L. Garkovich, and S. P. Oliver. 2017. Farm business and operator variables associated with bulk tank somatic cell count from dairy herds in the southeastern United States. J. Dairy Sci. 100:9298 9310. https://doi.org/10.3168/jds.2017-12767.

Dolecheck, K. A., W. J. Silvia, G. Heersche Jr., Y. M. Chang, D. L. Ray, A. E. Stone, B. A. Wadsworth, and J. M. Bewley. 2015. Behavioral and physiological changes around estrus events identified using multiple automated monitoring technologies. J. Dairy Sci. 98:8723-8731. https://doi.org/10.3168/jds.2015-9645.

Fraser, D., D. M. Weary, E. A. Pajor, and B. N. Milligan. 1997. A scientific conception of animal welfare that reflects ethical concerns. Anim. Welf. 6:187-205.

Gargiulo, J. I., C. R. Eastwood, S. C. Garcia, and N. A. Lyons. 2018 Dairy farmers with larger herd sizes adopt more precision dairy technologies. J. Dairy Sci. 101:5466-5473. https://doi.org/10 .3168/jds.2017-13324
Hogeveen, H., C. Kamphuis, W. Steeneveld, and H. Mollenhorst. 2010. Sensors and clinical mastitis - The quest for the perfect alert. Sensors (Basel) 10:7991-8009. https://doi.org/10.3390/s100907991.

Itle, A. J., J. M. Huzzey, D. M. Weary, and M. A. G. von Keyserlingk. 2015. Clinical ketosis and standing behavior in transition cows J. Dairy Sci. 98:128-134. https://doi.org/10.3168/jds.2014-7932.

Kamphuis, C., B. T. Dela Rue, and C. R. Eastwood. 2016. Field validation of protocols developed to evaluate in-line mastitis detection systems. J. Dairy Sci. 99:1619-1631. https://doi.org/10.3168/jds $.2015-10253$

Kamphuis, C., R. Sherlock, J. Jago, G. Mein, and H. Hogeveen. 2008. Automatic detection of clinical mastitis is improved by in-line monitoring of somatic cell count. J. Dairy Sci. 91:4560-4570. https: //doi.org/10.3168/jds.2008-1160.

Marra, M., D. J. Pannell, and A. Abadi Ghadim. 2003. The economics of risk, uncertainty and learning in the adoption of new agricultural technologies: Where are we on the learning curve? Agric. Syst. 75:215-234. https://doi.org/10.1016/S0308-521X(02)00066-5.

Mayo, L. M., W. J. Silvia, D. L. Ray, B. W. Jones, A. E. Stone, I. C. Tsai, J. D. Clark, J. M. Bewley, and G. Heersche Jr.. 2019. Automated estrous detection using multiple commercial precision dairy monitoring technologies in synchronized dairy cows. J. Dairy Sci. 102:2645-2656. https://doi.org/10.3168/jds.2018-14738.

Pereira, G. M., B. J. Heins, and M. I. Endres. 2018. Technical note: Validation of an ear-tag accelerometer sensor to determine rumination, eating, and activity behaviors of grazing dairy cattle. J. Dairy Sci. 101:2492-2495. https://doi.org/10.3168/jds.2016-12534.

Rogers, E. M. 1962. Diffusion of Innovations. The Free Press, London, UK.

Rogers, E. M. 1995. Diffusion of Innovations. 4th ed. The Free Press, New York, NY

Stone, A. 2017. Precision dairy farming technology solutions for detecting dairy cow disease to improve dairy cow well-being. $\mathrm{PhD}$ Dissertation. Department of Animal and Food Sciences, University of Kentucky.

Stone, A. E., B. W. Jones, C. A. Becker, and J. M. Bewley. 2017. Influence of breed, milk yield, and temperature-humidity index on dairy cow lying time, neck activity, reticulorumen temperature, and rumination behavior. J. Dairy Sci. 100:2395-2403. https://doi .org/10.3168/jds.2016-11607.

VanBaale, M. J., D. R. Ledwith, J. M. Thompson, R. Burgos, R. J. Collier, and L. H. Baumgard. 2005. Effect of increased milking frequency in early lactation with or without recombinant bovine somatotropin. J. Dairy Sci. 88:3905-3912. https://doi.org/10.3168/ jds.S0022-0302(05)73076-9.

Veenhoven, R. 1991. Is happiness relative? Soc. Indic. Res. 24:1-34. https://doi.org/10.1007/BF00292648.

von Keyserlingk, M. A. G., J. Rushen, A. M. de Passillé, and D. M. Weary. 2009. Invited review: The welfare of dairy cattle - Key concepts and the role of science. J. Dairy Sci. 92:4101-4111. https:// doi.org/10.3168/jds.2009-2326.

\section{ORCIDS}

A. E. Stone () https://orcid.org/0000-0001-5687-3394 